\title{
Os media como fator influenciador das escolhas alimentares das famílias
}

\section{Cristiana Ribeiro ${ }^{a}$, Cristina Mesquita ${ }^{b}$}

aEscola Superior de Educação, Instituto Politécnico de Bragança, Portugal, patricia_f.c.porto@hotmail.com, ${ }^{b}$ Escola Superior de Educação, Centro de Investigação em educação Básica, Instituto Politécnico de Bragança, Portugal, cmmgp@ipb.pt

\begin{abstract}
Resumo
Existem fatores influenciadores das escolhas das familias, sobre alimentação dos seus filhos, tais como a publicidade e as estratégias de marketing. Os documentos oficiais (como o Referencial de Educação para os media) $e$ algumas referências alertam para a importância da escola/jardim de infância na educação para os media a para os hábitos alimentares saudáveis. Porém, não parecem existir muitos estudos que se foquem no impacto da ação dos educadores, neste âmbito. Esta investigação teve como principal objetivo perceber qual a influência dos media nas escolhas alimentares das crianças e das suas famílias.

Este estudo realizou-se no decorrer do estágio pedagógico em contexto de Educação Pré-Escolar (EPE) e ensino do $10^{\circ}$ Ciclo do Ensino Básico (1. ${ }^{o}$ CEB). Neste artigo são utilizados apenas os dados dos questionários realizados às famílias. Neste sentido, a recolha e análise dos dados inscrevese numa perspetiva quantitativa, a partir de um questionário destinado aos pais.

Como resultado, observa-se que as famílias das crianças, influenciam os hábitos alimentares das crianças e que são influenciadas pela publicidade e pelas estratégias de marketing, embora não tenham muita consciência sobre isso.
\end{abstract}

Palavras chave: media, hábitos alimentares, práticas educativas.

\section{Escolhas alimentares das famílias e das crianças: preferências e influências}

Segundo Rodrigues (2008) são poucas as investigações, em Portugal, sobre a influência da publicidade nos hábitos alimentares das crianças. Por este fator, consideramos que o desenvolvimento de práticas educativas promotoras da construção de bons hábitos alimentares e, ao mesmo tempo, de construção da literacia para os media, em contexto educativo, poderia contribuir para uma reflexão pertinente, atual e necessária sobre o assunto. 
Desde a segunda metade do século XX, que se têm alterado os hábitos alimentares da população mundial (Silva et al., 2010). Também em Portugal se observaram tais mudanças, constatando-se a alteração dos hábitos do regime alimentar saudável e equilibrado (mediterrânico) para um regime alimentar hipercalórico e monótono (fast-food). A alimentação tem-se tornado cada vez mais desequilibrada, excessiva e de valor nutricional insuficiente. Em Portugal verifica-se um consumo elevado de alimentos hipercalóricos e um aumento do sedentarismo e, consequentemente, o aumento de doenças associadas a estes fenómenos. Neste sentido, nos pontos que se seguem procuraremos explorar a relação entre alimentação e saúde e os fatores que condicionam os hábitos alimentares saudáveis, explicitando a forma como se criam as preferências alimentares das crianças.

\subsection{Preferências alimentares das crianças}

As crianças têm preferências alimentares preestabelecidas que podem ter consequências para a sua saúde. Podemos definir preferência alimentar, como a tendência inata para eleger sabores salgados, doces e mais familiares e recusar sabores amargos, ácidos e novos alimentos (neofobia alimentar). Estas preferências resultam da aprendizagem realizada a partir da experimentação do sabor dos alimentos (Viveiros, 2012).

Verifica-se a preferência, das crianças, por alimentos de sabor adocicado, tais como refrigerantes, doces (como rebuçados, gomas, entre outros), lanches e refeições rápidas, alimentos ricos em carboidratos e gorduras saturadas. O consumo excessivo desses alimentos pode levar ao "deficit de fibras, vitaminas e sais minerais para o organismo" (Orsi \& Crisostimo, 2009, p. 4).

Orsi e Crisostimo (2009) comprovaram com a sua investigação que, nas horas do intervalo, para a realização das refeições intercalares, a maioria das crianças não leva fruta por vergonha, deixando-se influenciar pela opinião dos amigos. Observaram ainda que, na hora da compra, o rótulo do alimento, mais precisamente a imagem do mesmo, se manifesta como um fator decisivo para a compra. Os autores confirmaram também que a maioria das crianças sente vontade de consumir certos alimentos após observar a sua publicidade.

\subsection{Desenvolvimento de hábitos alimentares saudáveis}

O ambiente familiar, o contexto social e os media têm grande influência na definição dos hábitos alimentares das populações. Alguns autores, definem alimentação não só como sendo a satisfação de uma necessidade básica, mas também um meio de socialização, de prazer, de divulgação de cultura (Viveiros, 2012). A este propósito, Rodrigues (2008) refere que a alimentação contribui para saciar as necessidades a nível físico, emocional, social e económico. Neste estudo, entende-se por alimentação saudável aquela que promove o bemestar tanto físico como mental de um indivíduo, favorecendo a sua saúde e proporcionando uma boa qualidade de vida. A Direção Geral da Saúde (2015) publicou a dieta saudável 
como forma de alertar as populações para a importância de redefinir os seus hábitos alimentares. Neste enquadramento, o documento estabelece como alimentação saudável para as crianças, aquela que: tem em conta a idade das crianças e o equilíbrio entre as calorias ingeridas e as degastadas, o controlo dos açúcares, gorduras e sal, a promoção do consumo de frutas, vegetais e fibras .

A alimentação relaciona-se com as questões da saúde das pessoas. A elevada frequência de hábitos alimentares desadequados pode provocar problemas de saúde. As doenças crónicas, como por exemplo a obesidade, as doenças cardiovasculares, o cancro e a diabetes, podem ter a sua origem no tipo de alimentos que se consomem (Boog, 2004; Viveiros, 2012). As primeiras idades apresentam-se como fundamentais na prevenção destes problemas, uma vez que é na infância que os padrões e as preferências alimentares têm o seu início, mas que tendem a manter-se, ao longo da idade adulta.

Conforme salienta Viveiros (2012) os hábitos alimentares são influenciados por fatores internos, como sendo as "necessidades alimentares, valores e experiências pessoais, desenvolvimento psicológico, autoestima e imagem corporal" (p. 2) e fatores externos relacionados com a atmosfera familiar e as suas caraterísticas, as "atitudes parentais, conhecimentos nutricionais, valores sociais e culturais e os media" (p. 2).

A este propósito, Horta, Alexandre, Truninger, Teixeira e Silva (2013) referem que os hábitos alimentares são afetados por fatores como os contextos sociais, as interações, a publicidade, a influência de outros indivíduos, mas também por outros como a escola e os hábitos familiares. Alguns estudos apontam ainda a influência da relação entre os pares na compra de alimentos, principalmente definida pela popularidade do alimento. Parece existir uma tendência para se discriminar quem não consuma os alimentos mais populares (marcas dominantes do mercado), sendo acusados de "fora de moda", baratos e ridículos. Este tipo de escolhas é importante, pois coloca em risco a aceitação social (Stead, McDermott, Mackintosh, \& Adamson, 2011).

Para Belk (1974) o ambiente físico, focado no material e espaço onde é consumido, e o ambiente social, influência de outras pessoas, são fatores determinantes para o consumo. Nesta linha de análise Sobal e Wansink (2007) evidenciam que a diversidade, a visibilidade e a abundância de alimentos, bem como as porções, as formas e a disposição dos alimentos nos pratos, são também de grande influência no consumo. Isto significa que a estética dos alimentos, o sabor, a textura e, ainda, a apresentação e o cheiro também são tidos em conta no momento da escolha alimentar.

As crianças tendem a apresentar comportamentos neofóbicos. Como nos refere Viveiros (2012), entende-se por neofobia alimentar o medo do que é novo, o receio de consumir produtos que não se conhecem. Para deixar de existir este comportamento, a criança necessita ter contacto com um dado alimento entre cinco a dez vezes. A neofobia alimentar 
tem o seu pico por volta dos dois anos, estando as respostas neofóbicas mais relacionadas com alimentos como os vegetais, a fruta e a carne. No seu estudo Sullivan e Birch (1990) verificaram que crianças que em bebés foram amamentadas com leite materno têm menos probabilidade em desenvolver comportamentos neofóbicos, uma vez que, experimentam uma variedade de sabores e nutrientes (que advêm da alimentação da mãe) que irão influenciar as suas preferências alimentares futuras. Para influenciar positivamente as crianças, sobre novos alimentos, necessários à sua alimentação, importa apresentá-los de forma atrativa e, essencialmente, praticar bons comportamentos alimentares em frente das crianças.

No ponto seguinte referimos o papel da escola e da família na promoção de hábitos de alimentação saudável e na interpretação da publicidade.

\subsection{O papel da escola e da família}

Apesar de algumas investigações relativas às temáticas, já referidas, observam-se poucos estudos que se focalizem no papel da escola e, em particular, dos educadores e professores. A escola pode apresentar um papel fundamental na ação e inibição dos hábitos alimentares prejudiciais, embora, segundo Rodrigues (2008), exista uma ineficácia relativamente a este aspeto. As crianças passam grande parte do seu tempo na escola, por tal, é essencial que estas as apoiem na construção de uma visão consciente sobre o valor dos alimentos e, consequentemente, na adoção de estilos de vida e hábitos alimentares saudáveis. Tendo em conta esta visão, o Ministério da Educação de Portugal (ME, 2007) criou orientações rigorosas, relativas à oferta dos menus, nas cantinas, aos alimentos nos bares e máquinas de serviço rápido, destinados a crianças e adolescentes, nas escolas. Ainda assim, se revela difícil o cumprimento do objetivo, uma vez que no exterior das escolas toda a oferta permanece sem qualquer regulamentação (Horta et al., 2013; Rodrigues, 2008).

A família também tem um papel extremamente importante na criação de uma visão crítica das crianças relativamente à publicidade, dando-lhe explicações credíveis e úteis (Gonçalves, Moreira, Trindade, \& Fiates, 2013). Neste enquadramento, Viveiros (2012) considera que o papel da família é decisivo para a criação de hábitos alimentares saudáveis e padrões estáveis. Para tal, os pais devem tomar consciência das suas crenças, do "ambiente emocional durante as refeições", da "modelagem", e dos "fatores sóciodemográficos" que rodeiam a criança (p. 4). Neste sentido, quanto mais positivo for o ambiente familiar às refeições, maior será o interesse da criança pela ingestão de alimentos variados. As crianças tendem a escolher alimentos mais acessíveis, principalmente os prontos a comer. Por tal, os adultos devem ter esse fator em atenção e colocar ao acesso das crianças alimentos saudáveis. Além disso, Rodrigues (2008) refere que os pais devem controlar o tempo que as crianças assistem à TV, consoante a idade, devendo ser no máximo de duas horas. Nesses momentos os pais devem acompanhar os filhos, realizando 
comentários e críticas àquilo que visualizam e desligar a TV à hora das refeições. Devem, também, privilegiar outros entretenimentos como a leitura e o desporto.

Importa que os pais, educadores, professores e outros agentes educativos, conheçam o tipo de programas a que as crianças estão expostas, os estereótipos e conceções que veiculam, bem como os riscos que representam para a sua vida, para que os possam avaliar criticamente e intervir positivamente. Os resultados positivos observados no Canadá, relativos à introdução de educação para os media nos currículos escolares, leva-nos a acreditar que programas idênticos em Portugal podem ajudar as crianças a desenvolverem um pensamento crítico sobre a oferta que colocam à sua disposição (Morris \& Katzman, 2003).

Orsi e Crisostimo (2009) reforçam o papel do professor/educador na criação de um mundo cada vez mais democrático, recorrendo à descodificação dos seus códigos e mensagens. Rodrigues (2008) destaca a necessidade de reflexão dos educadores sobre a educação para os media, visto que muitas vezes, em contexto, ainda se premeia o sucesso dos seus alunos com guloseimas e doces. Acrescentam ainda, que importa que os educadores e professores revelem conhecimentos consistentes no âmbito das ciências naturais, para apoiarem as crianças na desconstrução de algumas conceções sobre este tema.

Como comprovaram Orsi e Crisostimo (2009), a maioria dos jovens e crianças não compreende as informações contidas nos rótulos dos alimentos. Assim, destacamos a importância da educação nutricional, por fornecer um conjunto de estratégias, que permitem ampliar os saberes das pessoas sobre o valor dos alimentos no sentido de mudar crenças, valores, representações, práticas, atitudes e relações sociais que se estabelecem em redor da alimentação. É fundamental que tenha como foco principal a saúde, o prazer e o convívio social, assim como o acesso económico e social de todos os cidadãos a uma alimentação com qualidade e porções adequadas. Com intuito de valorizar a cultura regional, as crianças, mesmo em idade pré-escolar, devem iniciar o conhecimento dos alimentos locais para, posteriormente, a partir do $1 .^{\circ} \mathrm{CEB}$ estudar as cadeias alimentares locais, sempre insistindo na análise crítica da sua alimentação (Boog, 2004).

\section{Metodologia e trajeto do estudo}

$\mathrm{Na}$ tentativa de garantir o que se encontra consagrado no artigo $17 .^{\circ}$ dos Direitos da Criança, onde é referido que as crianças devem ter "acesso a informação apropriada" (UNICEF, 1990), é essencial promover uma educação para os media. Neste sentido, este estudo teve como objetivo principal perceber a influência dos media nas escolhas alimentares das crianças e das suas famílias, para posteriormente desenvolver estratégias educativas promotoras de hábitos de alimentação saudável em contexto educativo. Este 
estudo realizou-se no decorrer do estágio pedagógico em contexto de Educação Pré-Escolar (EPE) e ensino do $1 .^{\circ}$ Ciclo do Ensino Básico (1. $\left.{ }^{\circ} \mathrm{CEB}\right)$. Trata-se de um estudo do tipo exploratório, com a utilização alguns elementos da investigação-ação. Tentamos perceber de que forma as práticas educativas poderiam contribuir para a construção de uma visão mais consciente das crianças e das famílias, relativamente à problemática em estudo. Este tipo de estudo segundo Gerhardt e Silveria (2009), "tem como objetivo proporcionar maior familiaridade com o problema, com vistas a torná-lo mais explícito ou a construir hipóteses" (p. 35).

Contudo, neste documento, apresentam-se apenas os dados tratados num dos instrumentos utilizados, o questionário aplicado às famílias das crianças em estudo, no sentido de preceber se estas sentem que a publiciadade é um fator influenciador das suas opções. A recolha e análise dos dados inscreve-se numa perspetiva quantitativa, a partir de um questionário destinado aos pais, cujas caraterístucas se explicitam de seguida.

\subsection{Técnicas e instrumentos de recolha de dados}

Para a recolha dos dados selecionamos as técnicas e instrumentos que consideramos mais adequadas. Um dos instrumento de recolha de dados que permitiu aceder à influência dos media nas escolhas alimentares das crianças e das suas famílias, como se referiu, foi o questionário.

O questionário garantiu a componente quantitativa da investigação, a única que se apresenta neste artigo. Foi selecionado pelo seu custo razoável, pela possibilidade de existirem questões iguais para todos os participantes e pela garantia de anonimato de todos eles. Nesta investigação os questionários foram aplicados individualmente e em papel.

Para a elaboração do questionário respeitamos as suas etapas de construção. Primeiramente procedemos à "justificativa", passando para a "definição dos objetivos", a elaboração das “questões e afirmações", a "revisão", a "definição do formato", o "pré-teste", a "revisão final” e por último a aplicação (Barbosa, 2015).

O questionário foi validado por dois especialistas e submetido a pré-teste com duas mães (uma com filhos a frequentar a creche e a outra o $1 .^{\circ} \mathrm{CEB}$ ). Este processo permitiu adaptar as questões e as formas de resposta de modo a tornar o instrumento mais claro. Este instrumentos era composto por por dois grupos de questões, um relativo às opções tomadas para os adultos e o outro relativo às opções dos adultos para as crianças. Procurava-se, com as questões obter dados sobre os comportamentos alimentares das famílias e das crianças e também sobre a publicidade como agente influenciador das escolhas. No total, foi aplicado a quarenta e sete famílias, das crianças que frequentavam as salas onde se desenvolvia a ação educativa, tendo sido obtidos trinta e dois questionários preenchidos. 
Os dados foram submetidos a tratamento estatístico. Foram transcritos para o Google formulário, importados para um ficheiro em formato Comma Separated Values (CSV) e processados recorrendo à ferramenta $\mathrm{R}$, procedendo-se à estatística descritiva.

\subsection{Apresentação e discussão dos dados}

Os questionários entregues às famílias das crianças da $\mathrm{EPE}$ e do $1 .^{\circ} \mathrm{CEB}$, tinham a mesma estrutura, o que nos permitiu realizar uma análise comparativa. Foram estudados um total de trinta e dois questionários, respondidos na sua grande maioria pelas mães das crianças (90,6\%). Das crianças envolvidas no estudo, 58,1\% das crianças eram do sexo feminino e $41,9 \%$ eram do sexo masculino, havendo com 6 anos 75\%, 15,6\% com 5 anos e 9,4\% com 7 anos.

Os dados revelam que as famílias e as crianças estavam expostas à publicidade, uma vez que $100 \%$, viam televesião ou usavam outros suportes digitais. $\mathrm{Na} \mathrm{EPE}$ as crianças estavam mais horas expostas à publicidade (3h/dia) do que no $1 .^{\circ} \mathrm{CEB}(1 \mathrm{~h} / \mathrm{dia})$. Os programas televisivos mais assistidos pelas crianças eram os desenhos animados.

A maior parte dos adultos $(59,4 \%)$ consideravam que a publicidade não influenciavam as suas escolhas alimentares nem as dos seus educandos, mas 40,6\% assumiram tal influência.

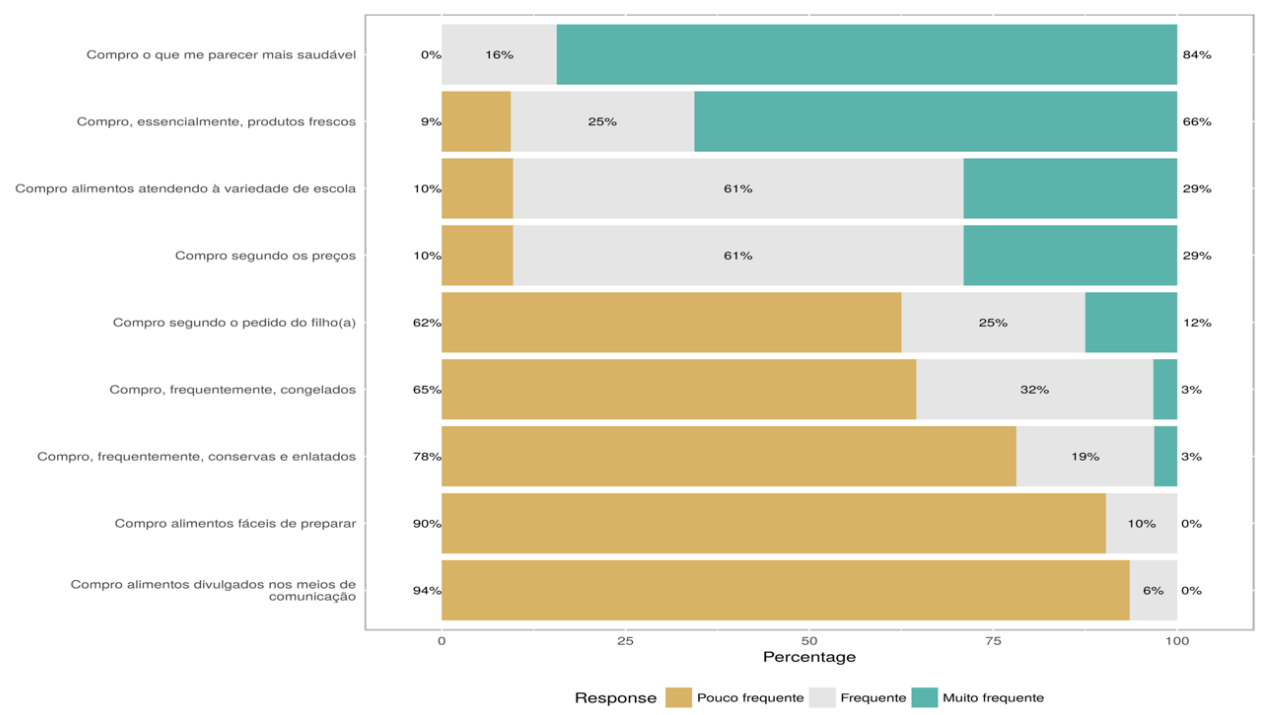

Gráfico 1 - Atitudes perante a seleção dos alimentos

Conforme se observa no Gráfico $1 \mathrm{e}$, enumerando de forma decrescente as decisões que prevalecem no momento de compra de alimentos, os adultos reconhecem que compram 
essencialmente o que lhes parece serem as escolhas mais saudáveis (84\%) e produtos frescos (66\%). No momento da compra, 29\% é influenciado pelos preços e atende à variedade de escolha, $12 \%$ admite comprar alimentos sugeridos pelo educando e $3 \%$ compra essencialmente alimentos congelados, conservas e enlatados. Os adultos revelam que quase nunca (94\%) compram alimentos pela sua divulgação na publicidade

Das seis refeições essenciais que se devem realizar diariamente, durante a semana, a ceia é a menos realizada (em que $34 \%$ a saltam), seguida do lanche da manhã (em que 9\% a saltam), pelas crianças.

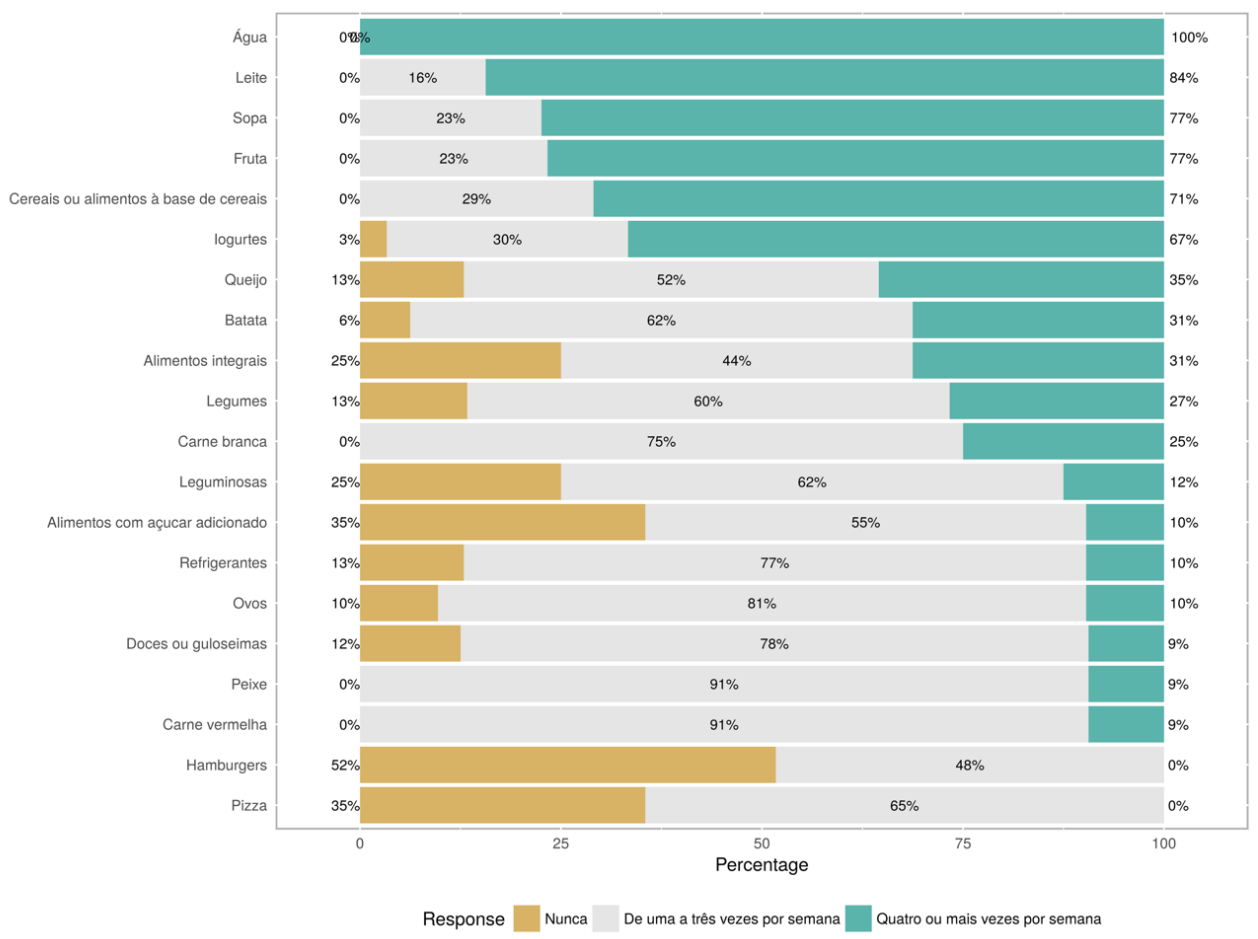

Gráfico 2 - Frequência de consumo dos alimentos

Os alimentos mais consumidos, quatro ou mais vezes por semana (Gráfico 2), foram a água $(100 \%)$, o leite $(84 \%)$, a sopa e a fruta $(77 \%)$, os cereais ou alimentos à base de cereais (71\%) e os iogurtes (67\%). Os alimentos selecionados como munca consumidos foram as hamburgers $(52 \%)$, as pizzas e os alimentos com açúcar adicionado (35\%) e os alimentos integrais e as leguminosas $(25 \%)$. 


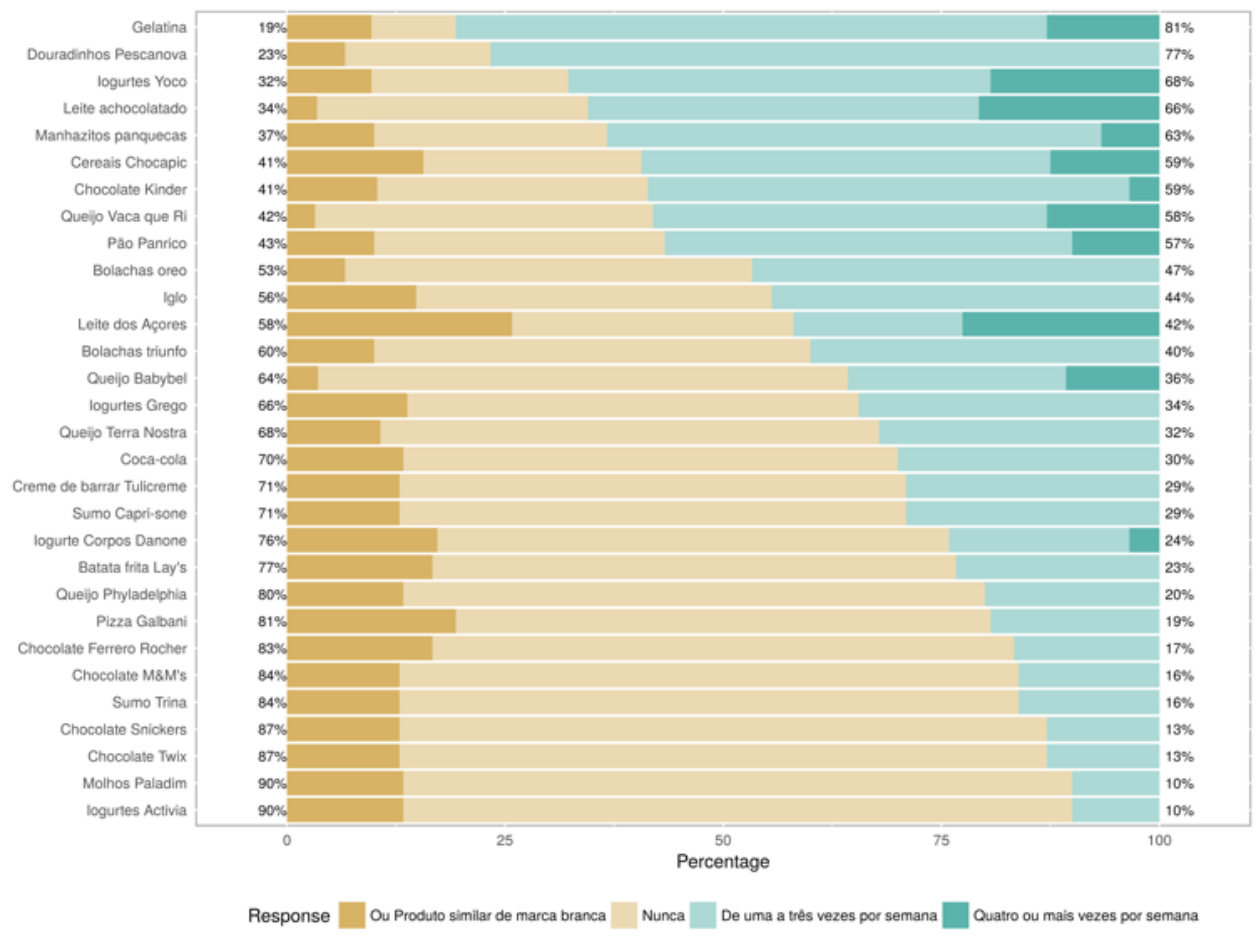

Gráfico 3 - Marcas consumidas

Relativamente às marcas mais consumidas, de quatro ou mais vezes por semana(Gráfico 3), o leite achocolatado, os iogurtes Yoco, foram o leite dos Açores, o queijo Vaca que Ri, cereais Chocapic, a gelatina, o queijo Babybel, o pão da Panrico, os Manhãzitos panquecas, o Chocolate Kinder e os iogurtes da Corpos Danone, foram as mais indicadas. Os alimentos nunca consumidos foram diversos, mas os dois mais escolhidos $(90 \%)$ foram os iogurtes Activia e os molhos Paladim. Todos os alimentos foram consumidos na sua versão de marca branca.

A maioria dos adultos considerava que nem eles (75\%) nem os seus educandos $(59,4 \%)$ eram influenciados pela publicidade, ainda assim, quando esta existia, era sobre as crianças (40,6\%). Alguns adultos assumiam que quando as crianças viam "um anúncio" passava uma "dinâmica" e, se existisse um "grau de qualidade" e "lhes agradasse", ia-lhes "induz[ir] o desejo de ter" e iam pedir para comprar. No momento da compra os adultos optavam pelo que lhes parecia mais saudáveis (84\%). Os alimentos mais consumidos quatro ou mais vezes por semana eram a água (100\%), o leite (84\%), a sopa (77\%), a fruta $(77 \%)$ e os cereais ou alimentos à base de cereais (71\%). Os alimentos nunca consumidos eram as hamburgers (52\%), os alimentos com açúcar adicionado e as pizzas (35\%), as leguminosas e os alimentos integrais (25\%). As marcas publicitadas mais consumidas, quatro ou mais 
vezes por semana, eram o Leite dos Açores (30\%), os iogurtes Yoco e o leite achocolatado (21\%), os cereais Chocapic (15\%), a gelatina (14\%) e o queijo Vaca que Ri (13\%). Três vezes por semana consumiam douradinhos da Pescanova (82\%), seguidos da gelatina (75\%), dos Manhãzitos panquecas (63\%) e do chocolate Kinder (62\%). Todos os alimentos publicitados eram consumidos, mas muitos deles na versão de marca branca. Os adultos (77,4\%) consideravam a alimentação do seu educando saudável.

Realizando uma comparação genérica entre o nível de EPE e $1 .^{\circ} \mathrm{CEB}$, pelos dados dos questionários, observamos que a alimentação das crianças $1 .^{\circ} \mathrm{CEB}$ era mais saudável que a das crianças EPE. Tais dados também se confirmam com as observações, uma vez que no 1. ${ }^{\circ} \mathrm{CEB}$ os sumos eram mais substituídos pelos iogurtes e observava-se um maior consumo de fruta. Ainda assim, não podemos referir que não existia influência da publicidade, uma vez que em todos os contextos se observou que as crianças levavam frequentemente, para o lanche, alimentos que eram alvo de publicidade mais intensiva, no período da recolha de dados.

\section{Considerações finais}

Com esta investigação concluímos que as crianças deste estudo são utilizadoras assíduas dos meios de comunicação. Pelas opções que realizam nas suas preferências, as famílias, parecem ser influenciadas pela publicidade, ainda que muitos pais não o assumam. A publicidade desperta a atenção das crianças com canções e a apresentação de um mundo ideal. Hoje em dia a publicidade encontra-se ainda mais presente na vida das crianças uma vez que se podem encontrar anúncios e spots publicitares em diferentes tipos de suportes digitais. Denotamos preocupação por partes dos pais em proporcionar uma alimentação saudável aos seus filhos, contudo nem sempre o conhecimento sobre o que deverá ser uma alimentação saudável, se adeuqa aos critérios definidos pela WHO.

Muitas vezes, as famílias fazem opções por alimentos idênticos mas de marcas brancas por se constituir como uma opção mais económica.

A publicidade divulga, quase na sua totalidade alimentos não saudáveis, com alto teor de açúcares, gorduras e sal. Os pais compram alguns alimentos pensando que são uma boa escolha.

Salienta-se deste estudo a importância de trabalhar a alimentação ao mesmo tempo que se trabalha para os fatores que a influenciam, sendo necessário, envolver os pais, apoiando-os na construção de uma visão mais ajustada sobre a alimentação saudável euma vez que são as os pais que tomam grande partes das decisões sobre a alimentação dos seus filhos. 


\section{Referências bibliográficas}

Assembleia Geral nas Nações Unidas. (1989). A Convenção sobre os Direitos da Criança. UNICEF. Obtido de http://www.unicef.pt/docs/pdf_publicacoes/convencao_direitos_crianca2004.pdf

Barbosa, E. (2005). Instrumentos de coleta de dados em pesquisas educacionais. Ser professor Universitário.

Obtido

de http://www.inf.ufsc.br/ vera.carmo/Ensino_2013 2/Instrumento_Coleta_Dados_Pesquisas_Educ acionais.pdf.

Belk, R. W. (1974). An Exploratory Assessment of Situational Effects in Buyer Behavior. Journal of Marketing Research, 11(2), 156-163. https://doi.org/10.2307/3150553

Boog, M. (2004). Contribuições da educação nutricional à construção da segurança alimentar. Saúde em Revista, 6 (13), 17-23.

Direção Geral da Saúde. (2015). Compromissos da indústria alimentar sobre alimentação, atividade fisica $e$ saúde. Obtido 4 de Janeiro de 2017, de https://www.alimentacaosaudavel.dgs.pt/activeapp/wp-content/uploads/2015/04/Compromissosda-industria-alimentar-sobre-Alimentacao-Atividade-Fisica-e-Saude.pdf

Gerhardt, T. E., \& Silveria T. S. (2009). Métodos de pesquisa. Porto Alegre: Editora da UFRGS

Ministério da Educação (2007). Circular n. ${ }^{\circ}$ 11/DGIDC/2007. Obtido de http://www.dge.mec.pt/sites/default/files/AccaoSocialEscolar/c_11_dgidc_2007.pdf

Gonçalves, J., Moreira, E., Trindade, B., \& Fiates, G. (2013). Transtornos alimentares na infância e na adolescência. Revista Paulista de Pediatria, 31(1), 96-103.

Horta, A., Alexandre, S., Truninger, M., Teixeira, J., \& Silva, V. (2013). Marketing e alimentação no espaço escolar: estímulos sensoriais/corporais e a sua apropriação pelas crianças. Sociologia, $6(13), 85-108$.

Morris, A. \& Katzman, D. (2003). The impact of the media on eating disorders in children and adolescentes. Paediatr Child Health, 8(5), 287-289

Orsi, L., \& Crisostimo, A. (2009). A influência dos meios de comunicação nos hábitos alimentares dos adolescentes. Acedido de: www.diaadiaeducacao.pr.gov.br/ portals/pde/arquivos/1613-8.pdf a 26/11/2016.

Rodrigues, I. (2008). Os jovens, a publicidade e a repercussão da mesma nos seus comportamentos alimentares. (Dissertação: Monografia). Universidade do Porto: Faculdade de Ciências da Nutrição e Alimentação, Porto. Recuperado https://repositorioaberto.up.pt/bitstream/10216/54445/3/123076_0855TCD55.pdf a 25/11/2016.

Silva, M., Vettoretti, N., \& Thomazello, M. (2010). Mudanças no hábito alimentar: O fenômeno da MCdonaldização. Livro de atas dos XIV encontro latino americano de iniciação científica e X encontro latino americano de pós-graduação, 1-6. 
Sobal, J., \& Wansink, B. (2007). Kitchenscapes, tablescapes, platescapes, and foodscapes. Influences of microscale built environments on food intake. Environment and Behaviour. Environment and Behaviour, 39(1), 124-142.

Stead, M., McDermott, L., Mackintosh, A. M., \& Adamson, A. (2011). Why healthy eating is bad for young people's health: identity, belonging and food. Social Science \& Medicine (1982), 72(7), 1131-1139. https://doi.org/10.1016/j.socscimed.2010.12.029

Viveiros, C. (2012). Estudo de comportamentos alimentares, preferências alimentares e neofobia alimentar em crianças pré-escolares e da eficácia de um programa de promoção de comportamentos alimentares saudáveis em contexto escolar: um estudo exploratório. (Dissertação de mestrado). Universidade de Lisboa: Faculdade de Psicologia, Lisboa. Recuperado de http://hdl.handle.net/10451/8063.

WHO. (2016b). Tackling food marketing to children in a digital world: trans-disciplinary perspectives. Dinamarca: WHO Regional Office for Europe.

Wilson, C., Grizzle, A., Tuazon, R., Akyempong, K., \& Cheung, C. (2011). Media and information literacy: curriculum for teachers. France: OCDE

Young, B. (2003). Does food advertising influence children's food choices? International Journal of Advertising, 22(4), 441-459. 